\title{
Redistribution and Group Participation: Experimental Evidence from Africa and the UK
}

\section{Marcel Fafchamps and Ruth Vargas Hill}

\begin{abstract}
We investigate whether the prospect of redistribution hinders the formation of efficiency-enhancing groups. We conduct an experiment in a Kenyan slum, Ugandan villages, and a UK university town. We test, in an anonymous setting with no feedback, whether subjects join a group that increases their endowment but exposes them to one of three redistributive actions: stealing, giving, or burning. We find that exposure to redistributive options among group members operates as a disincentive to join a group. This finding obtains under all three treatments-including when the pressure to redistribute is intrinsic. However the nature of the redistribution affects the magnitude of the impact. Giving has the least impact on the decision to join a group, while forced redistribution through stealing or burning acts as a much larger deterrent to group membership. These findings are common across all three subject pools, but African subjects are particularly reluctant to join a group in the burning treatment, indicating strong reluctance to expose themselves to destruction by others.
\end{abstract}

JEL classification: D03, O17

Keywords: Group membership, redistribution, experiment

\section{Introduction}

To the development practitioner observing local development failures, it is often frustrating that individuals do not cooperate to resolve them of their own accord. While some of these failures require financial

Marcel Fafchamps is a Professor at the Freeman Spogli Institute for International Studies, Stanford University, 616 Serra Street, Stanford, CA 94305. His email address is fafchamp@stanford.edu. Ruth Vargas Hill (corresponding author) is a Senior Economist in the Poverty and Equity Global Practice at the World Bank. Her email address is rhill@worldbank.org. The research for this article was mainly financed by the CGIAR Research Program on Policies, Institutions, and Markets (PIM). Supplemental funding for the 2014 UK sessions was provided by Stanford University. The opinions expressed here belong to the authors and do not necessarily reflect those of PIM or the CGIAR. We benefited from comments from Avner Greif, Pascaline Dupas, Edo Gallo, Eric Edmonds, Bruce Sacerdote, Erzo Luttmer, Stephane Straub, Eliana La Farrara, Alessandra Cassar, Bruce Wydick, Angelino Viceisza, and Eduardo Maruyama. We also received useful comments from conference participants at Oxford University and the Toulouse School of Economics and from seminar participants at the Nuffield College's Centre for Experimental Social Science, Stanford University, Dartmouth University, University of San Francisco, and University of Auvergne. We thank Hee Youn Kwon for her assistance implementing the 2012 experiment in Oxford and Nouhoum Traore for his assistance in implementing the experiment in Uganda and Nairobi. We are grateful to the lab at the Busara Center for Behavioural Economics, IPA, Nairobi, for their assistance with the Kenya experiment. We thank John Jensenius for his assistance with the 2014 sessions at the CESS lab in Oxford. Part of this work was undertaken while Ruth Hill was at the International Food Policy Research Institute. A supplementary online appendix for this article can be found at The World Bank Economic Review website. 
means that local communities do not have, others are, prima facie, amenable to collective action. Examples of local public goods relying on voluntary group participation include: parent-teacher associations (e.g., Coleman 1988; Pradhan et al. 2014); community-based organizations (e.g., Bernard, de Janvry, and Sadoulet 2010); and farmers' marketing cooperatives (e.g., Cook 1995; Fafchamps and Hill 2005). Considerable attention and effort have been devoted to the provision of such public goods through community development and other cooperative ventures. Yet success has been limited. Similar difficulties have been noted in the micro-enterprise sector, where lack of finance could be partially addressed through business partnerships and where market infrastructure and institutions could be improved through collective action (e.g., Grossman 2017).

Building on the work of Olson (1971) and Ostrom (1990), a large literature has emerged that seeks to understand the root causes of the underprovision of beneficial local public goods. In this literature, much attention has been devoted to certain possible causes, such as free-riding (e.g., Baland and Platteau 1995) and imperfect monitoring (e.g., Barr, Lindelow, and Serneels 2009). The literature has also argued that equity considerations and redistributive pressures affect collective action in heterogeneous groups (e.g., Baland and Platteau 1995; Banerjee, Iyer, and Somanathan 2005; Barr, Dekker and Fafchamps 2013), but this issue has received much less attention. This is the mechanism we focus on in this paper, drawing on the experimental literature on other-regarding preferences (e.g., Fehr and Schmidt 1999; Charness and Rabin 2002). In particular, we ask whether people would choose to eschew the returns to joining a group because of redistributive pressures that arise once in the group. We also examine whether the nature of the redistributive pressure affects this decision.

We design an original laboratory experiment to investigate whether redistributive actions hinder the formation of Pareto-improving groups. The experiment is designed such that there is no room for freeriding, and imperfect monitoring is not an issue. Subjects derive a purely individual benefit from joining a group but expose themselves to redistributive actions when they join. The experiment is designed to mimic, in a stylized way, the situation that arises when a small number of individuals join up to generate private benefits for them all, albeit not necessarily of equal magnitude. Examples include self-help schemes, producer and marketing cooperatives, and business partnerships. To focus on redistribution, we abstract from the incentive issues (e.g., free-riding, imperfect monitoring) generated by the production of the public good itself and assume that the group generates material benefits for all those who join.

Redistributive pressures in groups can take various forms. Requests for gifts and transfers first come to mind, as they have been extensively discussed in the development literature. If these requests cannot be turned down, ${ }^{1}$ they operate as an informal tax (e.g., Jakiela and Ozier 2016). We capture this possibility with a reverse dictator game: individual $i$ can take some of the endowment of individual $j$. Alternatively, it is possible that requests for gifts can be turned down but individuals feel an obligation to give to others in the group. We capture this with a generalized dictator game: individual $i$ can give some of his endowment to $j$ but at a given exchange rate (e.g., Zizzo 2003b; Fisman, Kariv, and Markovits 2007; Fisman, Jakiela, and Kariv 2015). Redistribution may also take a more destructive form driven by envy or spite (e.g., vandalism, sabotage, arson, or even witchcraft or poisoning). We capture this possibility by allowing individual $i$ to destroy some of $j$ 's endowment (e.g., Zizzo 2003a; Zizzo and Oswald 2001; Kebede and Zizzo 2011).

In our experiment, these three types of redistribution are introduced as three different treatments, dubbed "stealing," "giving," and "burning." Subjects must pay a price to destroy or appropriate someone else's endowment or to transfer part of their endowment to others. This price varies across treatments, as in a generalized dictator game. To eliminate reputational concerns and strategic considerations, play is anonymous throughout the experiment, and subjects are not provided any feedback about others' play 
during or after the experiment. The purpose of the experiment is to elicit behavioral heuristics toward unidentified members of the same subject pool.

We wish to test whether group formation is hindered by the prospect of "stealing," "giving," and "burning." To improve the external validity of our findings, we use two different subject populations in Africa: small farmers in Uganda and slum dwellers in Kenya. Furthermore, to verify that the results replicate across populations with potentially different norms and expectations about redistributive behavior, we include university students (in the UK), the type of subject population typically used for laboratory experiments.

We find many commonalities in redistributive behavior across the three subject pools: only a few subjects give away part of their endowment. Some subjects destroy the payoff of others, and many appropriate (part of) the endowment of others. There are also some differences: stealing is more prevalent among UK college students, giving is more common in the two African populations, and burning is least common among Nairobi slum dwellers.

Next we investigate how the burning, stealing, and giving treatments affect group formation. We find that subjects are less likely to join a group under any of the three treatments than under a control without redistribution. We also find that the type of redistribution matters. On average, joining is less frequent in the burning treatment, particularly when the cost of burning is low, and more frequent in the stealing and giving treatments. The similar rates of joining identified in the stealing and giving treatments suggest that it is not just the fear of taxation that prevents group formation. Furthermore, joining a group is not uniformly less common in subject populations that redistribute more. In the burning and stealing treatments, joining a group is less common among the Kenya and Uganda subjects even though they burn and steal (weakly) less. In the giving treatment, there is no difference in the propensity to join a group between sites even though giving is observed more often among African subjects. Although burning is uncommon in all three populations, a large proportion of African subjects refuse to join a group in the burning treatment-less so among UK subjects. In contrast, many UK subjects refrain from joining a group in the giving treatment, even though UK subjects on average give less.

Before revealing payoffs at the end of the experiment, participants are asked to estimate other players' propensity to burn, steal, and give. In the UK, participants who expect others to burn more are less likely to join, while among African participants, those who burn more are more likely to join a group in the burning treatment, suggesting that some subjects join a group in order to burn.

Taken together, the results indicate that group formation is hindered by the prospect of within-group redistribution. Among the African subjects, this effect is strongest for destructive redistribution induced by spite or envy. We also find that some people refrain from joining in the giving treatment, a finding that resonates with that of Lazear, Malmendier, and Weber (2012).

These findings complement the existing literature in several ways. Jakiela and Ozier (2016) use an experiment in rural Kenya to show that social pressure to share income causes individuals to forego investment returns. This is consistent with our finding that individuals are more likely to forego the return to joining a group when forced redistribution is perceived to be more likely.

Evidence from behavior outside the lab is also consistent with our findings. In Cameroon, 20 percent of borrowers state that they take on a costly loan in order to signal to others in their community that they do not have extra cash and cannot be asked for financial help (Baland, Guirkinger, and Mali 2011). Goldberg (2016) finds that the impact of a commitment savings product on saving behavior in Malawi is related to the need to resist demands to give to others, suggesting that people seek to avoid redistributive pressures. Our paper complements these findings by showing that people also avoid situations where giving is unsolicited and anonymous. One possible explanation is that, as in Della Vigna, List, and Malmendier (2012), individuals face an internal pressure to give and are willing to incur a reduction in payoff to avoid this internal pressure and, presumably, the associated guilt (e.g., Battigalli and Dufwenberg 2009). 
The paper is organized as follows. In section 2, we present the experimental design in detail. A conceptual framework is introduced in section 3 and is used to generate testable predictions about preference archetypes often used in economics. Experimental choices and joining decisions are analyzed in section 4. Section 5 concludes.

\section{Experimental Design}

The objective of the experiment is to identify individual motivations when joining a group that raises individual payoffs but allows redistribution among group members. To focus on motivations, we opt for an experimental design that eschews externalities, strategic interactions, reputation, and feedback. We avoid contextualizing the choices people make so as to minimize framing effects. To minimize cognitive load, choices are presented in graphical form (e.g., sliders or buttons) and the implications of subjects' choices on payoffs are automatically calculated for subjects. A detailed description of the experimental design is presented in supplementary online appendix S1, together with various screen shots.

The experiment is divided into three parts summarized in table $1 .^{2}$ Part 1 documents how subjects redistribute payoffs under three redistributive treatments: stealing, burning, and giving. The purpose of this part is to measure redistributive actions in the absence of self-selection. In part 2, subjects simply choose to join a group, thereby increasing their payoff. Its purpose is to document subjects' propensity to join a group with one of the redistributive treatments. If joining falls in part 3 relative to part 2, this constitutes evidence that the prospect of within-group redistribution discourages group formation. The three treatments are described below.

Table 1. Overall Structure of the Experiment

\begin{tabular}{lccc}
\hline & Part 1 & Part 2 & Part 3 \\
\hline Joining is a choice: & no & yes & yes \\
Number of rounds & 5 & 1 & 5 \\
Number of burning rounds & 1 & 0 & 1 \\
Number of stealing rounds & 3 & 0 & 2 \\
Number of giving rounds & 1 & 0 & 2 \\
\hline
\end{tabular}

Parts 1 and 3 are divided into five rounds each. Part 2 consists of just one round. In each round of the game, subjects are assigned to a set of three subjects: a triplet. This triplet changes at the beginning of each round. To ensure that this is well understood by participants, each subject is assigned a number at the beginning of the session, and the number of matched players is displayed on the screen when making decisions about burning, giving, or stealing (see screen shots in supplementary online appendix S1 for an illustration). There is no carry-over of earnings across rounds.

\section{Part 1}

In part 1, each subject is given the choice to destroy, appropriate, or transfer endowments within their triplet as follows. At the beginning of each round $t$, each subject $i$ receives an endowment $e_{i t}$ for that round. The subject is informed about both the endowment they receive and the endowments of the two other triplet members. The distribution of income is believed to be an important determinant of redistributive actions. For this reason, we vary the endowment that subjects receive: one subject receives a low endowment; one receives a medium endowment (twice the low endowment); and one receives a high

2 There were also three practice rounds (one for each treatment) in which individuals practiced the choices made in part 1. These do not affect final payoffs. The experiment was coded in z-tree (Fischbacher 2007). 
endowment (three times the low endowment). Who receives which endowment is varied randomly across rounds. This ensures that the value of endowments in previous rounds is orthogonal to play in the current round, and hence need not be controlled for in the analysis. We also include one round (out of five) in which all subjects receive the medium endowment.

After receiving their endowment for the round, each subject is informed about the redistribution opportunities for that round. The three treatments, dubbed "burning," "stealing," and "giving," all follow the same general design. In a given round $t$, all subjects in a triplet face the same treatment. This is common knowledge. Within a round, each player chooses an action independently of the others, as in a dictator game. One player is selected from each triplet at the end of the experiment, and the choices of the selected player determine the payoffs of the triplet in that round. It is never the case that a subject's payoff is affected by the decisions of more than one player, themselves included.

We now describe the payoffs to all three subjects if the choices of player $i$ are selected to determine final payoffs. In the burning treatment, subject $i$ chooses what share of subject $j$ 's endowment to destroy. This share is denoted $\tau_{i j t}$, with $0 \leq \tau_{i j t} \leq 1$ for each $j$. The payoff of subject $i$ can thus be written as:

$$
\pi_{i t}=e_{i t}-\gamma_{b t} \sum_{j \in N_{i t} i j t} \tau_{i j t} e_{j t}
$$

and subject $j$ 's payoff is given as:

$$
\pi_{j t}=e_{j t}\left(1-\tau_{i j t}\right)
$$

where $N_{i t}$ is the set of players in $i$ 's triplet in round $t$. Keeping in line with the dictator design, the actions of other subjects are set to zero when considering $i$ 's choice. ${ }^{3}$ Parameter $\gamma_{b t}$ captures the cost to $i$ of destroying the endowment of $j$ : it is the unit cost to $i$ of reducing $j$ 's payoff by $\$ 1$. The value of $\gamma_{b t}$ is randomly varied across rounds in order to vary the cost of burning and make redistribution more or less likely. It is common to all subjects in a given round $t$ and is common knowledge.

To illustrate, let $N_{i t}=\{2,3\}, e_{i t}=4, e_{2 t}=6, e_{3 t}=2, \gamma_{b t}=0.1$, and $\tau_{i 2 t}=50 \%$ and $\tau_{i 3 t}=0 \%$. Payoffs are:

$$
\begin{aligned}
& \pi_{i t}=4-0.1 \times(0.5 \times 6+0 \times 2)=3.7 \\
& \pi_{2 t}=6(1-0.5)=3 \\
& \pi_{3 t}=2(1-0)=2 .
\end{aligned}
$$

In this example, subject $i$ has destroyed part of subject 2's endowment, ensuring that 2 now receives a payoff lower than his own. Burning is always wasteful since it reduces aggregate payoffs by $\left(1+\gamma_{b t}\right) \sum_{j \in N_{i t}} \tau_{i j t} e_{j t}$. In the above example, the efficiency loss is 3.3-what subject 2 loses plus what $i$ pays to destroy subject 2's endowment. The higher the $\gamma_{b t}$, the larger the trade-off the subject faces between efficiency and redistribution. Player 2 is also asked to independently make choices about $\tau_{2 i t}$ and $\tau_{23 t}$, and similarly for player 3 .

In the stealing treatment, payoffs are given by:

$$
\begin{aligned}
& \pi_{i t}=e_{i t}+\left(1-\gamma_{s t}\right) \sum_{j \in N_{i t}} \tau_{i j t} e_{j t} \\
& \pi_{j t}=e_{j t}\left(1-\tau_{i j t}\right)
\end{aligned}
$$

3 This rules out situations in which players' choices are incompatible - as would arise if two players, say, were to spend all their own endowment to destroy the endowment of the others. In the z-tree code, we further impose the restriction that $\pi_{i t} \geq 0$ - a subject cannot spend more than his/her endowment $e_{i t}$ to destroy the payoff of other subjects. In practice, this restriction was never binding. No individuals chose to spend all of their endowment to destroy that of others. 
Here, $\tau_{i j t}$ is the share of $j$ 's endowment that $i$ appropriates and $\gamma_{s t}$ is the unit cost to $i$ of stealing $\$ 1$ from $j$. Since $0<\gamma_{s t}<1$ in our experiment, stealing is always wasteful and reduces aggregate efficiency. The value of $\gamma_{s t}$ is randomly varied across rounds, is common to all subjects in a given round $t$, and is common knowledge.

In the giving treatment, payoffs follow:

$$
\begin{aligned}
& \pi_{i t}=e_{i t}\left(1-\gamma_{g t} \sum_{j \in N_{i t}} \tau_{i j t}\right) \\
& \pi_{j t}=e_{j t}+\tau_{i j t} e_{i t}
\end{aligned}
$$

Here, $\tau_{i j t}$ is the share of its own endowment that $i$ gives to $j$ and $\gamma_{g t}$ is the unit cost to $i$ of increasing $j$ 's payoff by $\$ 1$. If $\gamma_{g t}<1$, giving is efficiency enhancing-it costs less than $\$ 1$ for $i$ to transfer $\$ 1$ to $j$-and vice versa if $\gamma_{g t}>1$. In the experiment, we always select a value of $\gamma_{g t}$ less than one, which means that giving is always efficiency-enhancing. The value of $\gamma_{g t}$ is randomly varied across sessions, is common to all subjects in a given round $t$, and is common knowledge.

\section{Part 2}

In the second part of the experiment, subjects are randomly allocated an endowment $e_{i t}$ and can elect to join a group. Subjects are told that if they join a group, the endowment $e_{i t}$ will be multiplied by $p_{t}$ and the round will end. The value of $p_{t}$ is always 1.5 in this part of the experiment. Subjects who do not join the group keep their initial endowment $e_{i t}$; subjects who join receive $p_{t} e_{i t}$ irrespective of whether others decide to join the group or not. ${ }^{4}$ Play ends after the subject decides whether or not to join.

The purpose of this part is to introduce subjects to the new action of joining a group. Any subject who understands this part of the game should join the group. There is only one round of play in part 2 .

\section{Part 3}

Part 3 combines parts 1 and 2 and consists of five rounds. As in part 1, subjects are randomly assigned to a triplet of players at the beginning of each round and are provided with an endowment $e_{i t}$. Subjects can form a group with others in their triplet.

As in part 2, subjects are told that if they join a group, their endowment will be multiplied by $p_{t}$. They are also told that subjects who join a group will have the opportunity to destroy, appropriate, or transfer within the group in a manner similar to part 1 . Payoff formulas are amended by multiplying $e_{i t}$ and $e_{j t}$ throughout by $p_{t}$-payoffs in the burning treatment now are:

$$
\begin{aligned}
& \pi_{i t}=p_{t}\left(e_{i t}-\gamma_{b t} \sum_{j \in N_{i t} i j t} \tau_{i j t} e_{j t}\right) \\
& \pi_{j t}=p_{t} e_{j t}\left(1-\tau_{i j t}\right)
\end{aligned}
$$

and similarly for payoffs in the stealing and giving treatments.

We expect the decision to join to increase with the return from joining and to decrease or increase with the subject's desire to participate in redistributive actions-depending on the subject's preferences. The value of $p_{t}$ is randomized across rounds to vary the return from joining. The sequence of treatments (burning, stealing, and giving) and $\gamma_{t}$ are also randomized across rounds. The distribution of $p_{t}$ and $\gamma_{t}$ are given in table 2 . The order of treatments, $p_{t}$, and $\gamma_{t}$ are randomized across sessions so that order effects cancel out and can be ignored in the analysis.

A subject chooses whether or not to join the group on the basis of the information provided. The subject then chooses how much to destroy, appropriate, or transfer within the group. Subjects who do

4 In other words, subject $i$ receives $p_{t} e_{i t}$ even if $i$ is the only one in the triplet to join a group. 


\begin{tabular}{|c|c|c|c|c|c|c|c|c|c|c|c|c|c|}
\hline \multicolumn{2}{|c|}{ Session type: } & \multicolumn{3}{|c|}{ A } & \multicolumn{3}{|c|}{ B } & \multicolumn{3}{|c|}{$\mathrm{C}$} & \multicolumn{3}{|c|}{$\mathrm{D}$} \\
\hline & Round & Treatment & $\gamma$ & $p$ & Treatment & $\gamma$ & $p$ & Treatment & $\gamma$ & $p$ & Treatment & $\gamma$ & $p$ \\
\hline \multirow[t]{5}{*}{ Part 1} & 1 & Burning & 0.05 & & Stealing & 0.5 & & Stealing & 0.9 & & Stealing & 0.9 & \\
\hline & 2 & Stealing & 0.7 & & Stealing & 0.7 & & Giving & 0.7 & & Stealing & 1.2 & \\
\hline & 3 & Stealing & 1 & & Burning & 0.05 & & Stealing & 0.3 & & Giving & 0.7 & \\
\hline & 4 & Stealing & 0.9 & & Stealing & 0.1 & & Stealing & 1.2 & & Burning & 0.05 & \\
\hline & 5 & Giving & 0.4 & & Giving & 0.4 & & Burning & 0.05 & & Stealing & 0.3 & \\
\hline Part 2 & 1 & & & 1.5 & & & 1.5 & & & 1.5 & & & 1.5 \\
\hline \multirow[t]{5}{*}{ Part 3} & 1 & Giving & 0.4 & 1.25 & Giving & 0.05 & 1.05 & Giving & 0.9 & 1.05 & Giving & 0.9 & 1.05 \\
\hline & 2 & Burning & 0.05 & 1.25 & Giving & 0.4 & 1.25 & Burning & 0.1 & 2 & Stealing & 0.5 & 1.25 \\
\hline & 3 & Stealing & 0.9 & 1.05 & Stealing & 0.3 & 1.5 & Stealing & 0.5 & 1.25 & Burning & 0.1 & 2 \\
\hline & 4 & Giving & 0.1 & 1.5 & Burning & 0.1 & 2 & Giving & 0.4 & 2 & Giving & 0.4 & 2 \\
\hline & 5 & Stealing & 0.9 & 1.5 & Stealing & 0.5 & 1.25 & Stealing & 0.3 & 1.25 & Stealing & 0.3 & 1.25 \\
\hline
\end{tabular}

Note: All session types (A, B, C and D) were repeated twice in Kenya and Uganda and once in the UK.

not join the group keep their initial endowment $e_{i t}$, as in part 2. Subjects who join the group can only affect the endowment of triplet members who have also joined the group, which implies that they observe which members of their triplet have joined a group in this round. However, as in part 1 , subjects are never told the burning, stealing, or giving choices of other participants. They are only told their final aggregate payoff at the end of the experiment. As the next subsection details, this does not allow subjects to infer the choices of other participants. Furthermore, the triplet sets are reshuffled for each round so that within part 3, a participant never plays against the same subjects twice. This rules out strategic play.

\section{Implementation}

Table 2 details the different values of $p_{t}, \gamma_{b t}, \gamma_{s t}$, and $\gamma_{g t}$ that were used in the experiment. These values were chosen so as to generate sufficient behavioral variation based on initial sessions run at Oxford University in Fall 2012. ${ }^{5}$ The table shows how the order of treatments are randomized across sessions to ensure that order effects cancel out in the analysis. ${ }^{6}$ The values of $p_{t}, \gamma_{b t}, \gamma_{s t}$, and $\gamma_{g t}$ are also randomized across sessions and rounds. The set of parameter vectors used in the experiments and other randomization details are common to all three countries.

The value of $p$ is set to ensure that joining a group is always Pareto enhancing for all players: $p>1$ in all cases, and is often large. Since the endowment of player $i$ is multiplied by $p$ whether others join or not, in the absence of redistribution it is always Pareto improving for a subject to join, irrespective of whether others join. Redistribution also has efficiency implications, however. In the giving treatment, giving is always efficiency enhancing since the cost of giving is set to a fraction $\gamma_{g}<1$ of the amount given. In contrast, redistribution through stealing, burning, or giving always reduces aggregate efficiency since the cost of burning $\gamma_{b}$ or stealing $\gamma_{s}$ is always larger than 0 .

5 These sessions used essentially the same z-tree code but experimented with different parameter values. We observed a high prevalence of stealing even for large values of gamma/high cost of stealing, so we retained fairly large $\gamma_{s t}$ for the main sessions reported here. For burning, large values of $\gamma_{b t}$ resulted in hardly any burning. Hence, we retained reasonably low values of $\gamma_{b t}$ to induce experimental variation. For the giving treatment, the initial Oxford sessions showed very low levels of giving and hardly any giving at all for $\gamma_{g t}$ values larger than one, that is, when giving is inefficient. Hence we only retain low values of $\gamma_{g t}$ for the main sessions.

6 Within a session the treatment order is the same for all subjects. This is necessary because triplets are reshuffled after each round, and hence it is the only way to ensure that all subjects play the same number of treatments. 
At the end of the experiment, three rounds are selected at random and payoffs are determined based on play during these three rounds only. Within each of the selected rounds, one of the subjects in each triplet is randomly selected. The choices made by that player determine the payoffs of all three players in the triplet. This setup is akin to a generalized three-player dictator game. It incentivizes subjects to regard each round as a separate decision, independent of other decisions already made. It also ensures that payoffs are always feasible.

Since there are three subjects in a triplet and three rounds are selected at random, in expectation each subject receives a payoff corresponding to one of their choices. ${ }^{7}$ Players who, in parts 2 and 3, elect not to join a group receive a payoff $\pi_{i t}=e_{i t}$. All these features are explained to subjects at the beginning of the experiment and illustrated during three practice games. Before being told their final payoff, subjects answer a short questionnaire about their expectations regarding burning, stealing, and giving by other participants.

The experiment was implemented in Kenya, Uganda, and the UK. In Kenya, 11 sessions were run in March 2013 at the Busara laboratory in Nairobi. In Uganda, nine sessions were run in April 2013 with coffee growers from the Masaka district. In the UK, four sessions were run in September 2014 at the Centre for Experimental Social Sciences at Nuffield College, Oxford. The number of participants in each session is 18. It follows that subjects in Kenya and the UK are more experienced with laboratory experiments than those in Uganda.

An additional set of sessions were run in Oxford in 2012. In these sessions, a protocol with more neutral words was used. Results from those sessions are briefly discussed in the empirical section. Our main findings hold across the two formulations of the experiment, suggesting that the framing did not significantly alter subject behavior, at least among UK students.

\section{Conceptual Framework}

In this section, we relate our experimental design to the literature and present testable predictions on how participants are expected to behave. We first discuss predictions regarding burning, stealing, and giving, conditional on being in a group, and then predictions about joining a group.

\section{Burning, Stealing, and Giving}

Once subjects are in a group, the decision structure of the giving and stealing treatments are generalized versions of the dictator game (DG) and reverse dictator game (RDG), respectively, except that giving or stealing decisions are made for two other subjects instead of one. The DG has been used in countless experiments. In pairwise cases, equal sharing often is the modal decision, with the rest of the distribution between zero and 50 percent. But there are some differences across cultures (e.g., Henrich et al. 2004). Giving in the DG is often interpreted as evidence of altruism or warm glow, although it could also reflect adherence to sharing norms, in which case decisions may be sensitive to normative framing.

7 Since selection of the decisive player is done independently for each of the three selected rounds, it is possible for one player's choice to be the selected one in more than one round. This raises the possibility that players may have considered all their decisions as part of a portfolio (as described in Bolton, Katok, and Zwick [1999]). Given this, a better design to eliminate portfolio considerations may have been to set the experiment such that each player would have his/her decision selected only once. We did not do that to avoid causing confusion, mostly because of the difficulty of discussing probability concepts with less sophisticated experimental subjects. This being said, even if subjects were capable of computing probabilities, portfolio effects are quite small. The true probabilities implied by the description of our experimental setting to subjects are as follows: $\operatorname{Pr}(0$ choices selected $)=29.6 \% ; \operatorname{Pr}(1$ choice selected $)=44.4 \% ; \operatorname{Pr}(2$ choices selected $)$ $=22.2 \% ; \operatorname{Pr}(3$ choices selected $)=3.7 \%$. From this we see that for subjects who understand probability well enough to calculate these values (something we were unable to do without a computer), they would conclude that the chance of affecting payoffs in multiple rounds is only 25.9 percent. From this we conclude that while we cannot fully rule out portfolio effects, they are probably negligible. 
List (2007), Bardsley (2008), and Jakiela (2013) all use RDGs. If subjects only care about the distribution of final payoffs, DG and RDG should yield equivalent behavior. The above-cited papers show that they do not: subjects often give more than they take. The common interpretation is that subjects behave as if the assignment of endowments generates quasi-ownership rights. Similar findings arise in dictator games where the giver and the recipient both receive an endowment: decisions depend on the initial division of endowments between players.

The generalized DG introduces an exchange rate parameter $\gamma$ between what is given and what is received. Andreoni and Miller (2002) and Andreoni and Vesterlund (2001) show that the amount given falls as the cost of giving increases, a finding that is consistent with altruism but not with warm glow. Null (2011), however, finds that a substantive fraction of subjects do not respond to $\gamma$, a behavior she interprets as indicative of warm glow. Fisman, Kariv, and Markovits (2007) use a three-person dictator game where the price of redistribution varies across rounds. They find that sharing decisions vary across subpopulations. To the best of our knowledge, no experiment has examined whether the amount taken in the reverse-DG responds to the cost of taking.

The burning game was first introduced by Zizzo and Oswald (2001) to investigate invidious preferences. ${ }^{8}$ The available evidence indicates that a small but non-negligible proportion of experimental subjects choose to destroy part of the endowment of others. This behavior is more common when the target of burning has a high endowment (e.g., Zizzo and Oswald 2001; Zizzo 2003a; Kebede and Zizzo 2011), a finding that is broadly consistent with inequality aversion (e.g., Fehr and Schmit 1999).

Building on the literature, we formally derive, in supplementary online appendix S2, how players are expected to behave in the burning, stealing, and giving treatments for six preference functions commonly used in the literature: selfish, altruistic, efficiency maximizing, invidious, inequality averse, and warm glow. These predictions were used to select parameters $p$ and $\gamma_{b}, \gamma_{s}$, and $\gamma_{g}$ in table 2 such that if a player consistently follows one of these archetypes, the combination of choices made during the experiment reveals their type. The hope is that by identifying a subject's preference type, we can better understand their decision to join a group.

\section{The Decision to Join}

The decision to join depends on the action that subjects plan to take and on what they expect other subjects to do. In the giving treatment, players should join if they have any of the six preference archetypes discussed so far. Those who give nothing should join because doing so multiplies their payoff by $p>1$ even if they expect to receive nothing. Those who wish to give should join because doing so increases their material payoff while, at the same time, increasing their utility through giving and, possibly, receiving. It is, however, possible that some subjects wish to avoid environments in which giving is possible, as documented for instance by Lazear, Malmendier, and Weber (2012). For such individuals, not joining may serve a guilt aversion purpose (e.g., Battigalli and Dufwenberg 2007).

In the burning treatment, only invidious players-and inequality-averse players with a low endowment-derive utility from burning. Other players join if the material gain from joining is larger than the expected loss from burning by other players. It follows that all players should be more likely to join if $p$ is large and if they expect less burning by others.

In the stealing treatment, things are more complicated. Players who plan to steal-according to table S2.1 in the supplementary online appendix (this is most of them)-derive an expected utility gain from joining if their choice determines final payoffs. But they also expect a utility loss if other players steal from them and their choice is not selected. It follows that the decision to join should increase in $p$ and decrease

8 The option to destroy someone else's payoff has also been studied in the context of games in which subjects first observe the action of others. Destruction is then interpreted as punishment for violating a social norm. Here, burning is decoupled from any punishment motivation. 
in the expectation of stealing by others. It should also decrease with the player's initial endowment in the round because someone with a low endowment has more to gain, and less to lose, from stealing. We present in supplementary online appendix S3 a detailed analysis of the decision to join for different preference archetypes.

\section{Experimental Results}

Descriptive tables are presented first, followed by regression analysis and test statistics.

\section{Descriptive Analysis}

Average play is summarized in table 3, while table 4 summarizes expectations relative to other subjects' behavior.

Table 3. Summary of Play

\begin{tabular}{|c|c|c|c|c|c|c|}
\hline & \multicolumn{2}{|c|}{ UK } & \multicolumn{2}{|c|}{ Kenya } & \multicolumn{2}{|c|}{ Uganda } \\
\hline & Mean & N.obs. & Mean & N.obs. & Mean & N.obs. \\
\hline \multicolumn{7}{|c|}{ Part 1: Joining imposed: } \\
\hline \multicolumn{7}{|c|}{ Average share of the endowment that is: } \\
\hline Burned in burning treatment & $7.8 \%$ & 144 & $4.8 \%$ & 198 & $10.7 \%$ & 162 \\
\hline Stolen in stealing treatment & $37.4 \%$ & 432 & $23.4 \%$ & 594 & $26.3 \%$ & 486 \\
\hline Given in giving treatment & $0.7 \%$ & 144 & $4.6 \%$ & 198 & $8.4 \%$ & 162 \\
\hline \multicolumn{7}{|l|}{ Part 2: Joining only: } \\
\hline Percentage of subjects joining: & $95.8 \%$ & 144 & $94.4 \%$ & 198 & $82.1 \%$ & 162 \\
\hline \multicolumn{7}{|l|}{ Part 3: Joining + transfers: } \\
\hline \multicolumn{7}{|l|}{ a. Percentage of subjects joining in: } \\
\hline Burning treatment & $82.6 \%$ & 144 & $59.6 \%$ & 198 & $42.0 \%$ & 162 \\
\hline Stealing treatment & $64.6 \%$ & 288 & $82.5 \%$ & 360 & $74.8 \%$ & 306 \\
\hline Giving treatment & $81.6 \%$ & 288 & $75.7 \%$ & 378 & $82.4 \%$ & 324 \\
\hline \multicolumn{7}{|l|}{ b. Average share of the endowment: } \\
\hline Burned in burning treatment & $5.9 \%$ & 111 & $6.7 \%$ & 97 & $17.6 \%$ & 39 \\
\hline Stolen in stealing treatment & $70.3 \%$ & 167 & $41.0 \%$ & 284 & $38.5 \%$ & 211 \\
\hline Given in giving treatment & $0.8 \%$ & 235 & $7.1 \%$ & 286 & $8.2 \%$ & 267 \\
\hline
\end{tabular}

Source: Authors' analysis based on data described in the text.

Note: The average share of the endowment that is burned, stolen, or given is calculated as the average of the choices made by the subject for the other two players in the group. We thus have one observation per subject per round.

We first examine behavior in part 1 . There are strong similarities across the three study populations: subjects burn little, they steal a lot, and they give very little. In the standard DG, players often give half of their endowment, de facto equalizing payoffs across players. Subjects in our giving treatment give much less than would be needed to equalize payoffs, even though giving is actually cheaper than in a DG game, since giving $\$ 1$ to another subject costs less than $\$ 1$. Our subjects also take much more than they give, a finding that is different from what has been observed elsewhere: subjects who play both the DG and the reverse-DG tend to take less than they give (e.g., List 2007; Bardsley 2008; Jakiela 2013). A salient difference with standard DG and reverse-DG experiments is that in our experiment, both players receive an endowment, even though endowments typically differ. This may blunt the pressure to share. Similarly, the fact that subjects are told they are in a group may make taking from others more acceptable. In contrast, levels of burning are broadly comparable to those reported in the existing literature (e.g., Zizzo 2003a; Zizzo and Oswald 2001; Kebede and Zizzo 2011). 
Table 4. Expectations of Others' Behavior

\begin{tabular}{|c|c|c|c|c|c|c|}
\hline & \multicolumn{2}{|c|}{ UK } & \multicolumn{2}{|c|}{ Kenya } & \multicolumn{2}{|c|}{ Uganda } \\
\hline & Mean & N.obs. & Mean & N.obs. & Mean & N.obs. \\
\hline \multicolumn{7}{|c|}{ Percentage of subjects responding "yes" when asked whether others will... } \\
\hline Burn their endowment & 29.6 & 144 & 42.4 & 198 & 51.5 & 145 \\
\hline Steal their endowment & 76.9 & 144 & 53.6 & 126 & 54.7 & 145 \\
\hline Give to them & 12.9 & 144 & 39.9 & 126 & 52.0 & 145 \\
\hline \multicolumn{7}{|c|}{ Percentage of subjects responding "yes" when asked whether others expect them to give. } \\
\hline Giving norm & 17.9 & 144 & 47.0 & 126 & 45.4 & 145 \\
\hline \multicolumn{7}{|c|}{ Ratio Expectation to Part 1 play } \\
\hline Burning & 3.8 & & 8.8 & & 4.8 & \\
\hline Stealing & 2.1 & & 2.3 & & 2.1 & \\
\hline Giving & 18.4 & & 8.7 & & 6.2 & \\
\hline
\end{tabular}

Source: Authors' analysis based on data described in the text.

Note: Some expectation questions were not asked to Kenyan participants in the first two sessions because of a technical glitch, hence the smaller number of observations. Differences between Oxford and the two African samples are statistically significant using either a $t$-test or a joint significance test in regressions of answers on country dummies with session clustering.

In part 2, joining increases one's payoff without affecting others and is a dominant strategy. We indeed observe that most participants join, even if a sizeable proportion of Ugandan subjects do not. This could indicate that they understand or trust the experiment less well than more experienced subjects from the UK and Kenya, or that they have a general distaste for joining a group.

In part 3, we see group participation drop relative to part 2. This is true for all three treatments across the three study populations. This implies that if joining a group opens new avenues for redistribution, individuals may refrain from joining even when it increases their endowment. This is true even though our experimental design rules out the kind of free-riding or imperfect monitoring that arises in public good games. This result is reminiscent of Jakiela and Ozier (2016), whose experimental subjects prefer a low payoff that is unobservable to others, a finding indicative of a redistributive "tax." These authors, however, are unable to identify precisely which type of redistribution subjects seek to avoid. By comparing joining under different treatments in our experiment, we can ascertain which type of redistribution is most problematic for group formation.

We begin with the giving treatment. In section 3, we argued that for this treatment, joining is a dominant strategy for any type of other-regarding preference, as long as subjects only care about material payoffs. Not joining can, however, be explained by guilt aversion (e.g., Battigalli and Dufwenberg 2009): it avoids regret at giving when others do not and shame at not giving when others do. Table 3 shows that joining is far from universal in the giving treatment, and is lower than in part 2 for two of the three populations. Since this cannot be reconciled with other-regarding preferences defined over final payoffs only, we conclude that a sizeable fraction of subjects have preferences over the process by which payoffs are assigned, and that these preferences lead them to abstain from joining a profitable group in the giving treatment.

For the burning treatment, we have argued that not joining is optimal only for those who expect a large proportion of their endowment to be burned. Selfish subjects, for instance, would have to expect 50 percent burning in order not to join a group. Table 1, part 1, shows that the average proportion of the endowment that is burned is much less than that in all three countries. Can we explain not joining by inaccurately high expectations of burning? Expectations are reported in table 4 . We see that 30 to 50 percent of the subjects expect some players to burn something. To compare expectations with behavior, we report, in the bottom half of the table, the ratio of expectations relative to actual play. We see that 
for burning, expectations are pessimistic, that is, they exceed the frequency of burning. ${ }^{9}$ From this we conclude that pessimistic expectations alone cannot account for subjects' reluctance to join a group in the burning treatment. A possible explanation is that subjects do not join in order to avoid the emotional cost of being burned. Joining, however, has an added appeal for invidious subjects who intend to burn others' endowment. For this reason, we would expect a higher incidence of burning among those who voluntarily join a group in the burning treatment. This is indeed what we find in the last panel of table 3 for two of the three study populations. The difference in incidence with part 1 is small, however, probably because the proportion of invidious subjects is small to start with.

For the stealing treatment, we have shown in section 3 that joining is optimal for subjects who intend to steal all of the endowment of others for the modal value of $\gamma_{s}$ and $p$. For subjects who do not intend to steal, joining is optimal under the same conditions as in the burning treatment, that is, if they expect less than 50 percent of their endowment to be taken on average. From table 4 we see that, except in the UK sessions, subjects on average ascribe a 50 percent chance that others would steal. From table 3 we know that, depending on the country, between 26 and 37 percent of the endowment is stolen on average. It follows that joining is optimal for most subjects, the main exception being UK subjects who expect a higher incidence of theft. From table 3, part 3, we see that joining in the stealing treatment is high but not universal. Except for UK subjects, who hold high expectations of stealing, joining is higher in the stealing treatment than in the burning treatment. We also find that the incidence of stealing is higher among those who join in part 3 than in part 1 - a finding prima facie consistent with the prediction that joining is more attractive for those who intend to steal.

Taken together, this evidence confirms that redistributive considerations are an impediment to the formation of an efficiency-enhancing group when joining facilitates redistribution among members. This arises even in the absence of free-riding or imperfect monitoring. Behind these findings seems to be some form of preference over process: in the burning treatment, subjects act as if they ascribe a subjective welfare cost to experiencing a destruction of their endowment by others that they could have avoided by not joining-something akin to regret aversion—and in the giving treatment, they demonstrate some reluctance to facing an intrinsic pressure to redistribute, as in Della Vigna, List, and Malmendier (2012). The surprise is that the fear of being "taxed" by others is not the only-or even the most perniciousconsideration: among the two African subject pools, joining is as common in the stealing treatment as in the giving treatment, and the difference between the two is not statistically significant.

\section{Regression Analysis}

While our main findings come out directly from the descriptive analysis, the reader may worry that they are affected by differences in parameter values across subjects and treatments. To address this concern, we replicate the various panels of table 3 in a regression format. A more detailed analysis also enables us to perform a finer analysis of the data. Robust standard errors are reported throughout, clustered at the session level.

\section{Burning, Stealing, and Giving}

We begin with burning, stealing, and giving choices. Results are shown in table 5 . The dependent variable is $\tau_{i j t}$, that is, the proportion of the endowment of player $j$ that is burned or stolen by $i$ or the proportion of $i$ 's endowment that is given to $j$. We pool decisions taken under part 1 -when joining is automatic-and part 3-when joining is optional. But we interact regressors with the optional joining dummy, which is equivalent to having different average decisions for parts 1 and 3.

9 Furthermore, what is reported in table 4 is the expectation of some burning, not the average amount burned, which presumably would not be 100 percent for those who burn. 
Table 5. Burning, Stealing, and Giving by Treatment

\begin{tabular}{|c|c|c|c|}
\hline & $\begin{array}{c}(2) \\
\text { Burning }\end{array}$ & $\begin{array}{c}(4) \\
\text { Stealing }\end{array}$ & $\begin{array}{c}\text { (6) } \\
\text { Giving }\end{array}$ \\
\hline Kenya & $\begin{array}{c}-0.069 \\
(-0.827)\end{array}$ & $\begin{array}{c}-0.094 \\
(-1.289)\end{array}$ & $\begin{array}{c}0.047 \\
(1.499)\end{array}$ \\
\hline Uganda & $\begin{array}{c}-0.108 \\
(-1.148)\end{array}$ & $\begin{array}{l}-0.147^{*} \\
(-1.750)\end{array}$ & $\begin{array}{c}0.044 \\
(1.278)\end{array}$ \\
\hline Dummy for optional joining & $\begin{array}{c}-0.023 \\
(-0.344)\end{array}$ & $\begin{array}{l}0.181 * * * \\
(4.674)\end{array}$ & $\begin{array}{c}0.000 \\
(0.053)\end{array}$ \\
\hline Kenya $\times$ optional joining dummy & $\begin{array}{c}0.052 \\
(0.867)\end{array}$ & $\begin{array}{l}-0.110 * * \\
(-2.095)\end{array}$ & $\begin{array}{c}0.016 \\
(1.524)\end{array}$ \\
\hline Uganda $\times$ optional joining dummy & $\begin{array}{c}0.068 \\
(0.918)\end{array}$ & $\begin{array}{l}-0.163 * * * \\
(-2.826)\end{array}$ & $\begin{array}{c}0.011 \\
(0.695)\end{array}$ \\
\hline$\gamma$ & $\begin{array}{c}-1.865 \\
(-1.033)\end{array}$ & $\begin{array}{l}-0.319 * * * \\
(-7.760)\end{array}$ & $\begin{array}{c}-0.008 \\
(-0.349)\end{array}$ \\
\hline Initial endowment & $\begin{array}{c}-0.173 \\
(-1.440)\end{array}$ & $\begin{array}{c}0.096 \\
(0.866)\end{array}$ & $\begin{array}{c}0.002 \\
(0.349)\end{array}$ \\
\hline Kenya $\times$ initial endowment & $\begin{array}{c}0.046 \\
(0.462)\end{array}$ & $\begin{array}{c}-0.116 \\
(-0.868)\end{array}$ & $\begin{array}{c}-0.020 \\
(-0.830)\end{array}$ \\
\hline Uganda $\times$ initial endowment & $\begin{array}{c}-0.101 \\
(-0.672)\end{array}$ & $\begin{array}{c}-0.128 \\
(-0.945)\end{array}$ & $\begin{array}{c}0.012 \\
(0.346)\end{array}$ \\
\hline Gain from joining & $\begin{array}{c}0.174 \\
(1.083)\end{array}$ & $\begin{array}{l}-0.339 \% \\
(-1.797)\end{array}$ & $\begin{array}{c}0.003 \\
(0.337)\end{array}$ \\
\hline Kenya $\times$ gain from joining & $\begin{array}{c}-0.013 \\
(-0.088)\end{array}$ & $\begin{array}{c}0.317 \\
(1.304)\end{array}$ & $\begin{array}{c}-0.023 \\
(-0.864)\end{array}$ \\
\hline Uganda $\times$ gain from joining & $\begin{array}{c}0.396 * \\
(1.730)\end{array}$ & $\begin{array}{c}0.307 \\
(1.207)\end{array}$ & $\begin{array}{c}0.012 \\
(0.351)\end{array}$ \\
\hline Endowment of other player & $\begin{array}{c}0.022 \\
(1.025)\end{array}$ & $\begin{array}{l}0.055^{* * *} \\
(3.208)\end{array}$ & $\begin{array}{l}-0.019 * \\
(-2.148)\end{array}$ \\
\hline Kenya $\times$ endowment of other player & $\begin{array}{c}-0.001 \\
(-0.032)\end{array}$ & $\begin{array}{l}-0.082 * * * \\
(-4.667)\end{array}$ & $\begin{array}{c}0.024 \\
(1.388)\end{array}$ \\
\hline Uganda $\times$ endowment of other player & $\begin{array}{c}0.034 \\
(0.814)\end{array}$ & $\begin{array}{c}0.012 \\
(0.508)\end{array}$ & $\begin{array}{c}0.014 \\
(0.848)\end{array}$ \\
\hline Dummy for rank $=2$ & $\begin{array}{c}-0.003 \\
(-0.230)\end{array}$ & $\begin{array}{c}-0.022 \\
(-1.491)\end{array}$ & $\begin{array}{c}-0.005 \\
(-1.077)\end{array}$ \\
\hline Constant & $\begin{array}{c}0.238 * \\
(1.707)\end{array}$ & $\begin{array}{l}0.635 * * * \\
(8.501)\end{array}$ & $\begin{array}{c}0.030 \\
(1.459)\end{array}$ \\
\hline Observations & 1,426 & 4,112 & 2,290 \\
\hline$R$-squared & 0.045 & 0.161 & 0.054 \\
\hline
\end{tabular}

Source: Authors' analysis based on data described in the text.

Note: The dependent variable is the share of the endowment of $j$ that is burned or stolen by $i$, or the share of the endowment of $i$ that is given to $j$. Each decision of subject $i$ is a separate observation. Each regression is estimated using a linear probability model. This ensures that each coefficient can be interpreted as the marginal effect of the regressor on average burning, stealing, or giving. Gain from joining $=(\mathrm{p}-1)^{*} \mathrm{e}_{\mathrm{i}}$. Standard errors are clustered at the session level. $t$-statistics appear in parentheses. $* * p<0.01 * p<0.05 * p<0.1$.

We introduce dyad-specific choice parameters as additional regressors. These parameters are organized into four groups: the price of burning, stealing, or giving $\left(\gamma_{b t}, \gamma_{s t}\right.$, or $\left.\gamma_{g t}\right)$, the initial endowment of the player $e_{i t}$, the gain from joining the group $e_{i t}\left(p_{t}-1\right)$, and the endowment of the other player $p_{t} e_{j t}$. To correct for differences in average endowment across sessions, we normalize the initial endowment, gain from joining, and endowment of the other players by the average endowment $\bar{e}_{S}$ in session $S .{ }^{10}$ Since choice

10 Formally, analysis is performed by replacing $e_{i t}$ with $\tilde{e}_{i t} \equiv \frac{e_{i t}}{\bar{e}_{S}}$, where $\bar{e}_{S} \equiv \frac{1}{N_{i, t \in S}} \sum_{i, t \in S} e_{i t}$ for session $S$. The gain from joining and the endowment of the other players are similarly divided by $\bar{e}_{S}$. 
parameters are orthogonal to each other by design, similar results are obtained if we limit the regressors to one set of choice parameters at a time. All choice parameters are interacted with country dummies, except for the $\gamma$ parameters, which show too little variation for interaction coefficients to be identified. We also include a dummy for the order in which choices are made. By design, subjects are always first asked about the other player with the largest initial endowment. The UK dummy is the omitted country category.

Results confirm that on average, there is significantly more stealing when joining is optional (part 3). There is also significantly less stealing when the price $\gamma$ of stealing is high. This finding contradicts purely selfish preferences, which dictate stealing everything irrespective of the value of $\gamma_{s}$, but it is consistent with altruistic preferences, inequality aversion, or warm glow. In contradiction with theoretical predictions presented in supplementary online appendix S2, we find no systematic variation in burning, stealing, or giving as a function of own endowment. This is difficult to reconcile with inequality aversion, that is, with the idea that subjects seek to correct differences between their endowment and that of the other player. We find less stealing when the gain from joining the group is larger and less giving to players with a large endowment, a finding consistent with altruism and inequality aversion. We also note less burning and stealing from the second $j$ player, the one with a lower endowment $p_{t} e_{j t}$.

All these results are robust to alternative specifications such as adding round dummies. There seems to be no learning across rounds, which is to be expected given that no information was fed back to participants during the experiment.

To investigate the findings further, we compare subjects' behavior to archetypes of selfish and otherregarding preferences discussed in the literature (i.e., altruistic and invidious preferences, inequality aversion, and warm glow). The details of the analysis are presented in supplementary online appendix S2. We find that the burning, stealing, and giving choices of most subjects do not satisfy any of these archetypes. This provides further confirmation that other-regarding preferences defined solely over final payoffs do a poor job of predicting behavior in our experiment. This opens the door to the possibility that subjects hold preferences over the process by which final payoffs are determined. More about this below.

\section{Joining}

Next we turn to the decision to join a group. We include regressors for the experimentally manipulated information known to the subject at the time the decision to join is made: the initial endowment of the subject $e_{i t}$, the gain from joining $e_{i t}\left(p_{t}-1\right)$, and the price of burning, stealing, or giving $\left(\gamma_{b t}, \gamma_{s t}\right.$ or $\left.\gamma_{g t}\right)$, depending on the treatment. Results are presented in table 6 separately for each of the three treatments, using a linear probability model with robust standard errors clustered by experimental session.

In the absence of redistribution issues, the aggregate efficiency gain from forming groups increases in $p_{t} \sum_{i} e_{i t}$. We therefore would hope that the propensity to join a group is not decreasing in $e_{i t}\left(p_{t}-1\right)$. Because a higher $p_{t}$ creates larger absolute differences between payoffs, however, it may also increase redistribution pressures. What do the results show?

For burning, we find in all three countries a lower propensity to join when $e_{i t}\left(p_{t}-1\right)$ is large. The effect is particularly large among African subjects. We also find that among African subjects, the size of the initial endowment $e_{i}$ has no additional effect on joining-the negative (but not significant) coefficient on $e_{i}$ is reversed for Kenya and Uganda. This suggests that subjects expect more burning when they gain more from joining, suggesting that individuals who receive a larger share of efficiency gains fear becoming a target of envy.

For stealing, none of the $e_{i t}\left(p_{t}-1\right)$ is statistically significant, suggesting that the magnitude of $p_{t}$ has no systematic effect on joining. But UK subjects with a large initial endowment $e_{i}$ are significantly less likely to join. For the two African populations, the effect of $e_{i t}$ is either small or not present: the coefficient on own 
Table 6. Joining by Treatment

\begin{tabular}{|c|c|c|c|}
\hline & $\begin{array}{c}\text { (1) } \\
\text { Burning }\end{array}$ & $\begin{array}{c}(2) \\
\text { Stealing }\end{array}$ & $\begin{array}{c}(3) \\
\text { Giving }\end{array}$ \\
\hline Kenya & $\begin{array}{c}0.346 \\
(1.630)\end{array}$ & $\begin{array}{l}0.467 * * * \\
(3.781)\end{array}$ & $\begin{array}{l}0.389 * * * \\
(11.820)\end{array}$ \\
\hline Uganda & $\begin{array}{l}-0.378 * * * \\
(-3.549)\end{array}$ & $\begin{array}{c}-0.079 \\
(-0.809)\end{array}$ & $\begin{array}{l}-0.026 \\
(-0.377)\end{array}$ \\
\hline Gain from joining & $\begin{array}{l}-0.288 * * \\
(-2.181)\end{array}$ & $\begin{array}{c}-0.061 \\
(-0.505)\end{array}$ & $\begin{array}{c}0.080 \\
(1.184)\end{array}$ \\
\hline Kenya $\times$ gain from joining & $\begin{array}{l}-0.474 * * * \\
(-3.224)\end{array}$ & $\begin{array}{l}-0.091 \\
(-0.219)\end{array}$ & $\begin{array}{l}-0.446 * * * \\
(-5.921)\end{array}$ \\
\hline Uganda $\times$ gain from joining & $\begin{array}{l}-0.852^{* *} \\
(-2.310)\end{array}$ & $\begin{array}{c}-0.452 \\
(-1.487)\end{array}$ & $\begin{array}{l}-0.446 * * * \\
(-6.903)\end{array}$ \\
\hline Initial endowment & $\begin{array}{c}-0.345 \\
(-1.618)\end{array}$ & $\begin{array}{l}-0.464 * * * \\
(-4.762)\end{array}$ & $\begin{array}{l}-0.110^{* *} \\
(-2.356)\end{array}$ \\
\hline Kenya $\times$ initial endowment & $\begin{array}{l}0.586 * * \\
(3.559)\end{array}$ & $\begin{array}{l}0.385 * \\
(2.438)\end{array}$ & $\begin{array}{l}0.136 * * \\
(2.223)\end{array}$ \\
\hline Uganda $\times$ initial endowment & $\begin{array}{c}0.537 \\
(1.546)\end{array}$ & $\begin{array}{l}0.353 * * \\
(2.512)\end{array}$ & $\begin{array}{c}0.077 \\
(0.827)\end{array}$ \\
\hline$\gamma$ & $\begin{array}{l}4.376^{*} \\
(1.840)\end{array}$ & $\begin{array}{l}-0.251^{* * *} \\
(-3.108)\end{array}$ & $\begin{array}{l}-0.210 * * * \\
(-3.150)\end{array}$ \\
\hline Constant & $\begin{array}{l}0.487 * * \\
(2.100)\end{array}$ & $\begin{array}{l}1.010 * * * \\
(10.760)\end{array}$ & $\begin{array}{l}0.882 * * * \\
(17.530)\end{array}$ \\
\hline Observations & 504 & 954 & 990 \\
\hline R-squared & 0.161 & 0.069 & 0.055 \\
\hline
\end{tabular}

Source: Authors' analysis based on data described in the text.

Note: The dependent variable is 1 if subject $i$ joins the group, 0 otherwise. Each regression is estimated using a linear probability model. This ensures that each coefficient can be interpreted as the marginal effect of the regressor on the probability of joining. Gain from joining $=(\mathrm{p}-1)^{*} \mathrm{e}_{\mathrm{i}}$. Standard errors are clustered at the session level. $t$-statistics appear in parentheses. ${ }^{* * *} p<0.01 * * p<0.05 * p<0.1$.

endowment is essentially canceled out by interaction terms with the Kenya and Uganda dummies. From this we conclude that UK subjects with a high $e_{i}$ refrain from joining in the stealing treatment, a finding that is in line with the idea that these subjects anticipate theft to be increasing with $e_{i t}$, as hypothesized in the theory section.

For the giving treatment, we find that African subjects are less likely to join when $e_{i t}\left(p_{t}-1\right)$ is large. We also find UK subjects to be less likely to join when their initial endowment $e_{i}$ is higher (this effect is reversed for African subjects). Taken together, the evidence indicates that subjects have a lower willingness to join when one's ability to give is higher. This finding is difficult to reconcile with altruistic preferences of any kind, but it can be accounted for by a reluctance to face an implicit pressure to redistribute, as in Della Vigna, List, and Malmendier (2012).

Table 6 also reports the sensitivity of joining to the cost of redistribution $\gamma$. We see that participants are more likely to join a group in the burning treatment if the price of burning $\gamma_{b}$ is high. This may reflect the fact that in that case, individuals expect less burning from others, making it safer to join the group. In contrast, participants are less likely to join a group if the price of stealing $\gamma_{s}$ is high. If subjects thought that a high $\gamma_{s}$ would deter stealing by others, they should be more likely to join. Since we observe the opposite, this suggests that the average subject joins in the hope of stealing from others and steals more when $\gamma_{s}$ is low, as we have seen in table 5. Finally, we find that subjects are less likely to join in the giving treatment if the price of giving $\gamma_{g}$ is high. Since $p_{t}>1$, joining is always optimal for any subject with consequentialist preferences. Hence, an explanation for this finding must rest in process preferences, but it is not clear which. 
Table 7. Joining, Expectations, and Past Play

\begin{tabular}{|c|c|c|c|}
\hline & $\begin{array}{c}(1) \\
\text { Burning }\end{array}$ & $\begin{array}{c}(2) \\
\text { Stealing }\end{array}$ & $\begin{array}{c}(3) \\
\text { Giving }\end{array}$ \\
\hline Expected burning/stealing/receiving & $\begin{array}{l}-0.268 * * \\
(-2.417)\end{array}$ & $\begin{array}{c}0.029 \\
(0.148)\end{array}$ & $\begin{array}{c}-0.066 \\
(-0.679)\end{array}$ \\
\hline Kenya $\times$ expected burning/stealing/receiving & $\begin{array}{l}0.440 * * \\
(2.536)\end{array}$ & $\begin{array}{c}0.168 \\
(0.836)\end{array}$ & $\begin{array}{r}0.219 * \\
(1.898)\end{array}$ \\
\hline Uganda $\times$ expected burning/stealing/receiving & $\begin{array}{c}0.278 * \\
(1.986)\end{array}$ & $\begin{array}{c}0.060 \\
(0.272)\end{array}$ & $\begin{array}{c}0.109 \\
(0.853)\end{array}$ \\
\hline Own past burning/stealing/giving & $\begin{array}{l}-0.290^{* *} \\
(-2.243)\end{array}$ & $\begin{array}{c}-0.021 \\
(-0.173)\end{array}$ & $\begin{array}{c}0.298 \\
(0.755)\end{array}$ \\
\hline Kenya $\times$ own past burning/stealing/giving & $\begin{array}{l}0.581 * * \\
(2.589)\end{array}$ & $\begin{array}{c}0.193 \\
(1.349)\end{array}$ & $\begin{array}{c}0.081 \\
(0.188)\end{array}$ \\
\hline Uganda $\times$ own past burning/stealing/giving & $\begin{array}{l}0.539 * * * \\
(2.913)\end{array}$ & $\begin{array}{c}0.307 \\
(1.675)\end{array}$ & $\begin{array}{c}-0.020 \\
(-0.048)\end{array}$ \\
\hline Other regressors (") & YES & YES & YES \\
\hline Observations & 487 & 829 & 830 \\
\hline$R$-squared & 0.214 & 0.098 & 0.083 \\
\hline
\end{tabular}

Source: Authors' analysis based on data described in the text.

Note: $(*)$ Other regressors included in the regressions are as in table 6: Kenya dummy, Uganda dummy, gain from joining, Kenya dummy $\times$ gain from joining, Uganda dummy $\times$ gain from joining, initial endowment, initial endowment $\times$ Kenya dummy, initial endowment $\times$ Uganda dummy, $\gamma$. The dependent variable is 1 if subject $i$ joins the group, 0 otherwise. Each regression is estimated using a linear probability model. This ensures that each coefficient can be interpreted as the marginal effect of the regressor on the probability of joining. Gain from joining $=(\mathrm{p}-1)^{*} \mathrm{e}_{\mathrm{i}}$. Standard errors are clustered at the session level. $t$-statistics appear in parentheses. $* * p<0.01 * p<0.05 * p<0.1$.

\section{Introducing Expectations}

As discussed in section 3, the decision to join should partly depend on how subjects expect other participants to behave. If they expect others to burn or steal their endowment, they should be more reluctant to join a group in these two treatments. In contrast, if they expect to receive a lot from others, they should be more willing to join in the giving treatment. To investigate this idea, we re-estimate table 6 with additional regressors for subjects' expectation of play by other participants, on its own and interacted with country dummies.

For this regression to be fully convincing, we must control for the subject's intended play. To illustrate the issue, remember that people who intend to steal have an incentive to join in the stealing treatment. Now imagine that subjects who expect others to steal also steal a lot themselves. If we control for expectations but not own play, we may falsely assign to a high expectation of stealing by others a behavior that is in fact driven by an intention to steal from others. To correct for this, we construct a variable that summarizes each participant's burning, stealing, and giving decisions made in part 1 . Since subjects receive no feedback about others' play during the experiment, play in part 1 should be a good proxy for intended play in part 3.

Regression results are summarized in table 7 . We find no pattern regarding the stealing treatment. African subjects are slightly more likely to join in the giving treatment when they expect to receive more, as hypothesized earlier. But the effect is only significant for Kenya. Results are stronger in the burning treatment: joining is less likely for UK subjects who expect more burning, as would be predicted by theory. But the effect is absent among Kenyan and Ugandan subjects who, other things being equal, are much less likely to join in a burning treatment. We also find that UK subjects who burned a lot in part 1 are less likely to join a burning treatment in part 3 . This effect, however, is reversed in the other two countries: subjects who burned more in part 1 are more likely to join a group in the burning treatment. This latter finding is consistent with theoretical predictions, suggesting that their desire to burn partly motivates their decision to join. 
In results not shown here, we also examine whether expectations of others' play help predict one's own play in part 1 and part 3 of the experiment. We find in the UK study population a strong association between own play and own expectation of others' play. This is true in all treatments and in both parts of the experiment, although in the two African study pools, this association is weaker.

\section{Conclusions}

In this paper, we have reported the results from a laboratory experiment conducted with different subject pools in Kenya, Uganda, and the UK. We test whether subjects are less likely to join a group when doing so increases their endowment but exposes them to one of three redistributive treatments: burning, stealing, or giving. We also test whether people in a group choose to destroy or steal the endowment of others and whether they choose to give some of their endowment to others. The experimental setting precludes any feedback between subjects during and at the end of the experiment. Play is anonymous, and subjects never play twice with the same subject within the same part of the experiment.

We find a lot of commonality across the three subject populations in terms of redistributive behavior: little giving and burning, more stealing. Our main finding is that exposure to redistributive pressures among group members operates as a disincentive to join a group. Perhaps unexpectedly, this finding obtains under all three treatments, including when the pressure to redistribute is purely intrinsic, as in the giving treatment. We also find much less giving in our giving treatment than in a typical dictator game and more appropriation in the stealing treatment than in a typical reverse-dictator game. Burning, on the other hand, is broadly consistent with existing experimental evidence. The data also show that all subjects expect more burning, stealing, and giving than actually takes place. These findings are common across all three subject pools, indicating that they are not specific to African or UK subjects.

By drawing Kenya and Uganda subjects from a broad cross-section of urban and rural Africans, we hope that their actions in the experiment are indicative of the behavioral motivations of individuals similar to them outside the lab. If so, our results suggest that the formation of efficiency-enhancing groups is hindered whenever group membership opens the door to redistributive pressures, including the internalized pressure to give.

Although much behavior is similar across the African and UK subjects, there are some differences. Why this is the case is unclear, since these subject populations differ along several dimensions. We find that UK subjects are less likely to join the group when in the stealing treatment, and that African subjects are particularly concerned about payoff destruction by others. In fact, only 42 percent of Ugandan subjects join a group under the burning treatment, even though burning is fairly uncommon in practice. If we combine this finding with the observation that burning expectations would have to be higher than they appear to be to explain not joining, we are left with the conjecture that African subjects derive a large utility loss from exposing themselves to the prospect of payoff destruction by others-a type of behavior suggestive of regret aversion. This is confirmed by the fact that African subjects are least likely to join in the burning treatment when they have a larger endowment or gain more from joining a group.

While our findings are broadly consistent with earlier work on sharing norms and redistributive "taxes" (e.g., Jakiela and Ozier 2016; Goldberg 2016), they demonstrate that redistribution need not take the form of an imposed transfer of the type allowed in the stealing treatment. Other forms of redistribution matter equally if not more, especially destructive forms of redistribution in which payoffs are dissipated. In spite of the thousands of miles separating our subjects from Native Americans of the Northwest, this observation brings to mind the potlatch, a practice by which economic surplus is ceremonially burned or otherwise destroyed on a regular basis (e.g., Mauss 1923-1924).

We also note in passing that UK subjects tended to steal more and give less than subjects in either African sample. African subjects expect less stealing and more giving than the UK subjects. Why this is the case is unclear, but it does not support the view either that individuals in Africa are uniformly less 
altruistic $^{11}$ or that redistributive pressures are unusually strong in Africa, at least compared to the UK college students participating to our experiment. This makes our findings about group formation even more striking.

Our findings have relevance for public policy, particularly in Kenya and Uganda and other parts of the developing world, where formalized social insurance systems are weak and where various forms of ad hoc redistribution are relied upon to help those in need. The widespread presence of informal redistribution has, for instance, been listed by Ugandan policymakers as justification for not investing in formal, public insurance. The results of our work indicate that informal redistribution can have adverse effects. Redistributive pressures discourage the formation of groups (e.g., business partnerships, farmers' cooperatives, self-help groups) that bring about Pareto gains.

\section{References}

Andreoni, J., and J. Miller. 2002. "Giving According to GARP: An Experimental Test of the Consistency of Preferences for Altruism.” Econometrica 70 (2): 737-53.

Andreoni, J., and L. Versterlund. 2001. "Which Is the Fair Sex? Gender Differences in Altruism.” Quarterly Journal of Economics 116 (1): 293-312.

Baland, J.-M., C. Guirkinger, and C. Mali. 2011. "Pretending to Be Poor: Borrowing to Escape Forced Solidarity in Cameroon." Economic Development and Cultural Change 60 (1): 1-16.

Baland, J.-M., and J.-P. Platteau. 1995. Halting Degradation of Natural Resources: Is There a Role for Rural Communities? Oxford: Food and Agriculture Organization, Clarendon Press.

Banerjee, A., L. Iyer, and R. Somanathan. 2005. "History, Social Divisions and Public Goods in Rural India." Journal of the European Economic Association 3 (2-3): 639-47.

Bardsley, N. 2008. “Dictator Game Giving: Altruism or Artefact?” Experimental Economics 11 (2): 122-33.

Barr, A., M. Dekker, and M. Fafchamps. 2013. "The Formation of Community Based Organizations in Sub-Saharan Africa: An Analysis of a Quasi-Experiment” Mimeo. Department of Economics, Oxford University, Oxford.

Barr, A., M. Lindelow, and P. Serneels. 2009. "Corruption in Public Service Delivery: An Experimental Analysis." Journal of Economic Behavior and Organization 72 (1): 225-39.

Battigalli, P., and M. Dufwenberg. 2007. "Guilt in Games.” American Economic Review 97 (2): 170-76.

- 2009. "Dynamic Psychological Games.” Journal of Economic Theory 144 (1): 1-35.

Bernard, T., A. de Janvry, and E. Sadoulet. 2010. "When Does Community Conservatism Constrain Village Organizations?” Economic Development and Cultural Change 58 (4): 609-41.

Bolton, G. E., E. Katok, and R. Zwick. 1999. "Dictator Game Giving: Rules of Fairness Versus Acts of Kindness.” International Journal of Game Theory 27 (2): 269-99.

Charness, G., and M. Rabin. 2002. “Understanding Social Preferences with Simple Tests.” Quarterly Journal of Economics 117 (3): 817-69.

Coleman, J. S. 1988. "Social Capital in the Creation of Human Capital.” American Journal of Sociology 94 (Suppl): S95-120.

Cook, M. L. 1995. “The Future of US Agricultural Cooperatives: A Neo-Institutional Approach.” American Journal of Agricultural Economics 77 (5): 1153-59.

Della Vigna, S., J. A. List, and U. Malmendier. 2012. "Testing for Altruism and Social Pressure in Charitable Giving." Quarterly Journal of Economics 127 (1): 1-56.

Fafchamps, M., and R. V. Hill. 2005. "Selling at the Farmgate or Traveling to Market." American Journal of Agricultural Economics 87 (3): 717-34.

Fehr, E., and K. M. Schmidt. 1999. "A Theory of Fairness, Competition and Cooperation.” Quarterly Journal of Economics 114 (3): 817-68.

Fischbacher, U. 2007. "z-Tree: Zurich Toolbox for Ready-Made Economic Experiments.” Experimental Economics 10 (2): 171-78. 
Fisman, R., P. Jakiela, and S. Kariv. 2015. "How Did Distributional Preferences Change During the Great Recession?” Journal of Public Economics 128: 84-95.

Fisman, R., S. Kariv, and D. Markovits. 2007. "Individual Preferences for Giving.” American Economic Review 97 (5): $1858-76$.

Goldberg, J. 2016. "The Effect of Social Pressure on Expenditures in Malawi.” Mimeo. University of Maryland, College Park, MD.

Grossman, S. 2017. The politics of order in informal markets: Evidence from Lagos. Mimeo. Stanford University, Stanford, CA.

Henrich, J., R. Boyd, S. Bowles, C. Camerer, E. Fehr, and H. Gintis. 2004. Foundations of Human Sociality: Economic Experiments and Ethnographic Evidence from Fifteen Small-Scale Societies. Oxford: Oxford University Press.

Jakiela, P. 2013. "Equity vs. Efficiency vs. Self-Interest: on the Use of Dictator Games to Measure Distributional Preferences." Experimental Economics 16 (2): 208-21.

Jakiela, P., and O. Ozier. 2016. "Does Africa Need a Rotten Kid Theorem? Experimental Evidence from Village Economies." Review of Economic Studies 83 (1): 231-68.

Kebede, B., and D. J. Zizzo. 2011. "Envy and Agricultural Innovation: An Experimental Case Study from Ethiopia." CSAE Working Paper Series 2011-06, University of Oxford, Centre for the Study of African Economies, Oxford, UK.

Lazear, E. P., U. Malmendier, and R. A. Weber. 2012. "Sorting in Experiments with Application to Social Preferences." American Economic Journal Applied 4 (1): 136-63.

List, J. A. 2007. "On the Interpretation of Giving in Dictator Games." Journal of Political Economy 115 (3): 482-93.

Mauss, M. 1923-1924. "Essai sur le don. Forme et raison de l'échange dans les sociétés archaïques” [An essay on the gift: the form and reason of exchange in archaic societies]. L'Année Sociologique, second series. Presses Universitaires de France, Paris, France.

Null, C. 2011. "Warm Glow, Information, and Inefficient Charitable Giving." Journal of Public Economics 95 (5-6): 455-65.

Olson, M. 1971. The Logic of Collective Action: Public Goods and the Theory of Groups, rev. ed. Cambridge, MA: Harvard University Press.

Ostrom, E. 1990. Governing the Commons: The Evolution of Institutions for Collective Action. Cambridge: Cambridge University Press.

Pradhan, M., D. Suryadarma, A. Beatty, M. Wong, A. Gaduh, A. Alishjabana, and R. P. Artha. 2014. "Improving Educational Quality Through Enhancing Community Participation: Results from a Randomized Field Experiment in Indonesia." American Economic Journal: Applied Economics 6 (2): 105-26.

Zizzo, D. J. 2003a. "Money Burning and Rank Egalitarianism with Random Dictators.” Economics Letters 81 (2): 263-66.

- 2003b. "Inequality and Procedural Fairness in a Money Burning and Stealing Experiment." Economics Series Working Papers 155, University of Oxford, Department of Economics, Oxford, UK.

Zizzo, D. J., and A. J. Oswald. 2001. “Are People Willing to Pay to Reduce Others' Incomes?” Annales d'Economie et de Statistique 63/64: 39-65. 